\title{
Bilingualism confers advantages in task switching: Evidence from the dimensional change card sort task*
}

\author{
HWAJIN YANG \\ Singapore Management University \\ ANDREE HARTANTO \\ Singapore Management University \\ SUJIN YANG \\ Ewha Womans University, South Korea
}

(Received: August 02, 2016; final revision received: June 22, 2017; accepted: August 09, 2017; first published online 9 October 2017)

\begin{abstract}
We examined the influence of bilingualism on task switching by inspecting various markers for task-switching costs. English monolinguals and Korean-English bilinguals completed a modified Dimensional Change Card Sort task based on a nonverbal task-switching paradigm. We found advantages for Korean-English bilinguals in terms of smaller single-task (pure-block) switch costs and greater reactivation benefits than those of English monolinguals. However, bilingual advantages in mixing costs were relatively weak, and the two groups did not differ on local switch costs. Notably, when we approximated the cue-based priming effect in single-task (pure) blocks, we found no evidence that the locus of bilingual advantages in task-switching performance is attributable to a basic cue-priming effect. Taken together, our results suggest that bilingualism is conducive to task switching via facilitation in control processing, including inhibition of proactive interferences and efficient adaptation to abstract task-set reactivation.
\end{abstract}

Keywords: bilingualism, Dimensional Change Card Sort (DCCS), task switching, local switch cost, mixing cost, single-task switch cost, reactivation benefit

\section{Introduction}

Bilinguals experience unique linguistic challenges. Specifically, bilinguals must spontaneously and frequently alternate between two language systems, especially when they converse with interlocutors who are speaking different languages. Bilinguals' language switching is conceptually and functionally analogous to task switching - i.e., moving back and forth between different tasks, thoughts, goals, or mental operations, depending on environmental demands (Monsell, 2003). Given the overlap between language switching and complex task switching, recent research has noted the potential for a transfer of bilinguals' language switching facility to nonverbal task switching (e.g., Prior \& Gollan, 2011), which is an important aspect of executive control abilities that regulate thoughts and actions for goal-directed behaviors (Diamond, 2013).

Evidence from neurocognitive studies implies that bilinguals' long-term practice of language switching may play a positive role in task switching, because similar brain regions have been reported to be associated with bilinguals' task- and language switching (Garbin, Sanjuan, Forn, Bustamante, Rodriguez-Pujadas, Belloch, Hernandez, Costa \& Avila, 2010; Weissberger, Gollan,

\footnotetext{
*This research was supported by a grant from the Ministry of Education Academic Research Fund Tier 1 conferred on the first author (14-C242-SMU-031).
}

Bondi, Clark \& Wierenga, 2015). However, behavioral studies that examined the effect of bilingualism on task switching have yielded inconsistent findings. More importantly, given that the typical task-switching paradigm involves (a) local switch costs, which result from switching between different task sets in mixed blocks, and (b) mixing costs, which stem from monitoring conflict and coordinating and maintaining competing task sets in mixed blocks, in contrast to single-task (pure) blocks (Prior \& Gollan, 2011), previous studies have not reached a consensus regarding which types of task-switching costs are influenced by bilingual experience. Since the literature suggests that these two costs tap into different aspects of executive control (e.g., Rubin \& Meiran, 2005), understanding the influence of bilingualism on these costs can shed light on aspects of the mechanism that underlies bilingual advantages in executive control.

Given that bilinguals must constantly monitor two languages that are activated simultaneously, some researchers argue for bilingual advantages in mixing costs - which are also referred to as "global switch costs" or "global costs" (e.g., Barac \& Bialystok, 2012; Gold, Kim, Johnson, Kryscio \& Smith, 2013; Wiseheart, Viswanathan $\&$ Bialystok, 2016. For a detailed summary of previous studies, see Appendix 1). Specifically, Wiseheart et al. (2016) found that bilinguals showed smaller mixing costs - as indicated by slower responses on task-repeat trials in mixed-task blocks than on task-repeat trials in

Address for correspondence:

Sujin Yang, Ph.D. Department of Psychology, Ewha Womans University, 52 Ewhayeodae-gil, Seodaemun-gu, Seoul, South Korea

sujinyang@ewha.ac.kr 
single-task pure blocks - than monolinguals; however, no group differences were observed for switch costs. Similarly, Barac and Bialystok (2012) found that bilingual children had significantly smaller mixing costs than monolinguals, but the two groups did not differ in switch costs (i.e., local costs). In addition, several critical aspects of bilingualism (e.g., age of acquisition, language balance, frequency of switching, and number of native languages) have been found to attenuate mixing costs (Paap, Johnson \& Sawi, 2014; Soveri et al., 2011; Yow \& Li, 2015). Since mixing costs are known to require control abilities to monitor task cues and maintain two competing task and response sets (Braver, Reynolds \& Donaldson, 2003; Rubin \& Meiran, 2005), they are used to index the functioning of global control mechanisms that involve a monitoring system (Braver et al., 2003; Koch, Prinz \& Allport, 2005; Kray \& Lindenberger, 2000; Rubin \& Meiran, 2005).

Other studies, however, have found no evidence for bilingual advantages in mixing costs. Instead, they argue for bilingual advantages in local switch costs, as indicated by slower responses on task-switch trials than nonswitch trials within mixed blocks. Since bilinguals' language switching requires skills similar to those used in task switching - that is, the ability to reconfigure language sets upon switching and inhibit interference from an irrelevant language set (e.g., Houtzager, Lowie, Sprenger \& De Bot, 2015) - it is plausible that bilinguals' language switching is closely related to local switch costs. Consistent with this view, Prior and MacWhinney (2010) found significant bilingual advantages in local switch costs - but not in mixing costs - when they compared English monolinguals with fluent bilinguals who speak English and various other languages. Similarly, Prior and Gollan (2011) found bilingual advantages in local switch costs, but only among Spanish-English bilinguals who engaged in more frequent language switching than Chinese-English bilinguals. However, this effect was only present when parents' education levels - a proxy measure of socioeconomic status (SES) - was controlled for. Considering that local switch costs are largely driven by rapid and frequent switching between two competing tasks, the literature suggests that local switch costs reflect transient local control mechanisms (Braver et al., 2003; Logan \& Bundesen, 2003; Mayr \& Kliegl, 2003; Rubin \& Meiran, 2005) that consist of (a) task-set reconfiguration, which is the ability to shift from the current task to perform another task (Rogers \& Monsell, 1995), and (b) inhibition of proactive interference, which is the ability to regulate interference from the previously performed task (Wylie \& Allport, 2000).

Further complicating the picture, still more studies have challenged these findings; several failed to find bilingual advantages in either mixing costs or switch costs (e.g., Paap \& Greenberg, 2013; Paap \& Sawi,
2014). Moreover, using a new intermittent task-cue paradigm, in which cues were presented intermittently after an unpredictable number of trials, Hernández, Martin, Barcelo, and Costa (2013) failed to replicate bilingual advantages in local switch costs, but they did find bilingual advantages in restart costs, which refer to the response delay on the first cued trial relative to the subsequent trial of the same task that is not preceded by the cue (Poljac, Koch \& Bekkering, 2009). Hernández et al. further argue that bilingual advantages in restart costs should be attributed to monitoring and facilitation of task-set reactivation, which is based on the ability to reactivate and update the task set at hand; restart costs, therefore, are thought to implicate both global and local processing.

In view of these discrepancies in the literature, we aimed to reinvestigate the bilingual effect on task switching, with three goals. Our primary goal was to reinvestigate the subject by adopting a modified switching task, the Dimensional Change Card Sort task (DCCS; Frye, Zelazo \& Palfai, 1995; Yang, Yang \& Isen, 2013). Because the modified DCCS has features that previous switching tasks lacked, it addresses previous studies' methodological concerns in three major respects, as described below.

The first notable feature of the DCCS is that it eliminates potential memory load for storing task rules and response keys (see Fig. 1). Specifically, participants do not need to remember details associated with response keys, because two reference pictures (a red truck and a blue star) that correspond to the location of the response key to press remain visible at the bottom of the screen throughout the test - i.e., with the red truck at the bottom left and the blue star at the bottom right. Hence, the DCCS is designed to measure the target construct (task switching) more precisely, while minimizing the potential noise that can be caused by extraneous and irrelevant cognitive demands on working memory and individual differences in working memory capacity (e.g., Weissberger et al., 2015). Since working memory demands are not directly relevant to task-switching costs (e.g., Rubin \& Meiran, 2005), any variation in response time (RT) caused by working memory load may simply reflect noise, which in turn obscures the detection of any potential group differences in task switching. Hence, it is important to reduce the task's potential working memory demands to adequately capture group differences in task-switching performance.

A second unique feature of the DCCS is its use of a relatively small number of trials (a total of 60 test trials), whose goals are (a) to attenuate potential practice effects and, at the same time, (b) maintain an adequate degree of task novelty, which requires that well-developed cognitive routines be modified in a new way. Given that practice is shown to mitigate task novelty that relates to the prefrontal 
A.

\section{Single task (pure-block) switch cost Local-switch cost}
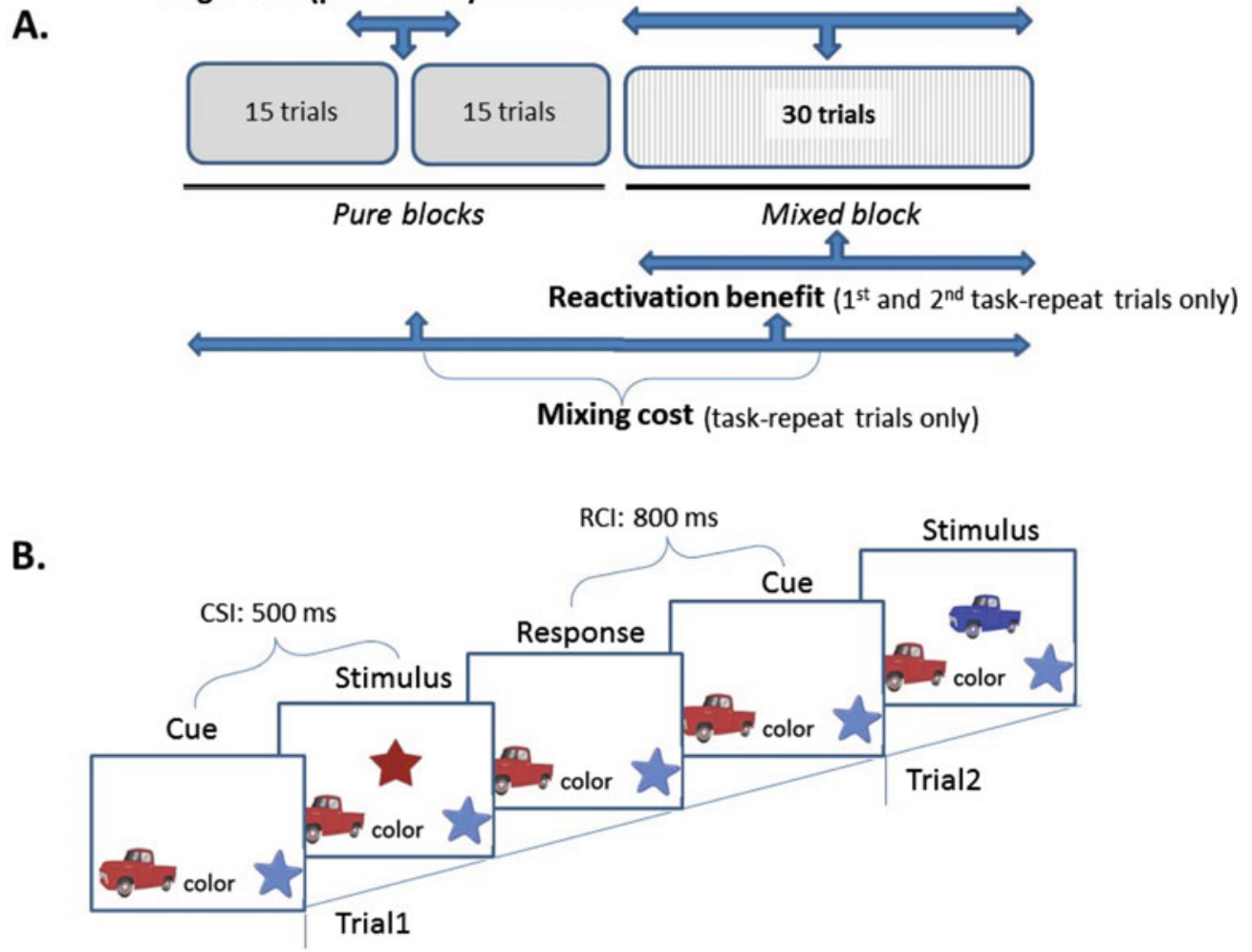

Figure 1. (color online) The top panel (A) illustrates the main experimental procedure. The bottom panel (B) is a schematic depiction of the Dimension Change Card Sort (DCCS) task used in the study (adapted from Diamond \& Kirkham, 2005). CSI: Cue-Stimulus Interval; RCI: Response-Cue Interval.

cortex and demands a relatively high level of cognitive control (for a review, see Goldberg, Podell \& Lovell, 1994; Gray, 2001), previous studies have demonstrated that practice via many trials allows for largely automatic completion of the task without engaging control processes (e.g., Shiffrin and Schneider, 1977). In line with this notion, practice has been found to directly influence task-switching costs (e.g., Minear, Shah \& Park, 2002; Strobach, Liepelt, Schubert \& Keisel, 2012). Therefore, a minimum number of trials - which enhances task novelty and imposes relatively high demand on control processes - can contribute to the task's sensitivity in capturing any group differences that arise from more cognitively taxing tasks (Costa, Hernández, Costa-Faidella \& SebastiánGallés, 2009; Qu, Low, Zhang, Li \& Zelazo, 2016; Yang \& Yang, 2016).

The last notable feature is that the DCCS employs overlapping response mapping to increase its sensitivity to local switch and mixing costs. Overlapping response mapping occurs when each response key is assigned to two responses on the color vs. shape tasks (e.g., "red" and "triangle"), while non-overlapping response mapping occurs when each response key is assigned to only one response (e.g., "red"). Although both overlapping and non-overlapping response sets tap into control processes, the literature suggests that an overlapping response set critically affects the magnitude of switch and mixing costs, because it imposes high cognitive demands on (a) taskset reconfiguration, which underlies switch costs (for a review, see Kiesel, Steinhauser, Wendt, Falkenstein, Jost, Philipp \& Koch, 2010, and Mayr, 2001), and (b) inhibition of interference from competing tasks and response sets, which in turn influences mixing costs (Gade \& Koch, 2014; Mayr, 2001; Meiran, 2000; Rubin \& Meiran, 2005; Yang, Hartanto \& Yang, 2016). As demonstrated by previous studies (e.g., Costa et al., 2009; Qu et al., 2016; Yang \& Yang, 2016), higher task demand increases the task's sensitivity to detect bilingual advantages in cognitive control. These methodological aspects of the DCCS differ from the typical color-shape task-switching paradigm, and can, therefore, render the task more sensitive for detecting potential group differences in control abilities.

Our second goal for the study was to examine the boundary conditions that may modify the effect of bilingualism on local switch costs. Several studies have demonstrated the absence of bilingual advantages in local switch costs (e.g., Hernández et al., 2013; Wiseheart et al., 2016). However, given that bilinguals' language switching occurs either instantaneously or sporadically, 
depending on interlocutor or context, it is likely that different types of language switching may entail the use of different cognitive mechanisms. Specifically, bilinguals' instantaneous and recurrent language switching seems comparable to local switch costs, which involve both task-set reconfiguration and inhibition of interference. In contrast, sporadic and occasional language switching seems comparable to somewhat different switch costs - i.e., which entail greater proactive interference because longer use of one language should create greater interference when switching to another (Durston, Thomas, Worden, Yang \& Casey, 2002).

To closely examine various facets of local switch costs, therefore, we conceptualized a single-task switch cost that is analogous to sporadic and occasional language switching. Following the literature (Diamond \& Kirkham, 2005; Yang \& Yang, 2014), we calculated single-task switch costs by comparing average differences in RT on the last two trials in the first pure block and the first two trials in the second pure block; note that the two pure blocks consist of trials based on a single task. Since the first pure block creates strong expectation of a given task, successful performance on the initial trials of the second pure block should require the ability to resist the strong proactive interference of a prior task. In light of studies that find support for bilingual advantages in resisting proactive interference (e.g., Bialystok \& Feng, 2009), bilingualism likely confers benefits on singletask switch costs because they impose higher demands on proactive interference than task-set reconfiguration. Studying single-task switch costs, therefore, may be useful in delimiting bilingual advantages in switch costs that are induced by proactive control, which is regarded as a global control mechanism.

Our third goal was to examine whether bilingualism facilitates task-set reactivation, which is a core aspect of reactive control at a local level. To this end, we conceptualized reactivation benefits as assessing one's ability to adaptively reactivate a relevant task set in the mixed block despite its unpredictability. In general, reactivating the same task set in a predictable manner should be beneficial, since it saves processing time (Hernández et al., 2013). However, this can be challenging if the task to be reactivated cannot be foreseen. Despite this unpredictability, if benefits accrue to the subsequent repeated trial (i.e., reactivation benefit), this may indicate adaptive and efficient reactivation and monitoring of task sets for each rapidly recurring, but unexpected, task repetition. This conceptualization of reactivation benefit differs from Hernández et al.'s (2013) restart cost, in which task-set reactivation occurs in a predictable sequence. Noting that bilinguals' language switching in everyday life occurs unpredictably, especially when initiated by interlocutors (Green \& Abutalebi, 2013), bilinguals may efficiently recruit adaptive control processes to choose and reactivate the context-appropriate language, even when the two languages are intermixed and alternate randomly, as in the mixed block. Given that reactivation benefits are based on trial-by-trial adjustment of task-switching performance in a reactive manner, bilingual advantages in reactivation benefits will further strengthen the link between bilingualism and local control mechanisms.

In sum, we compared English monolinguals with Korean-English bilinguals in task switching as assessed by the modified DCCS, which yields four task-switching markers: typical (a) local switch and (b) mixing costs, and newly conceptualized (c) single-task switch costs and (d) reactivation benefits. In line with studies that have found bilingual advantages in global control, we hypothesized that bilingualism would attenuate mixing costs via better monitoring at a global level. Similarly, given the evidence in support of bilinguals' better control of proactive interference in particular (Bialystok \& Feng, 2009), we hypothesized that bilingualism would also benefit singletask switch costs that are attributed more to inhibition of proactive interference using global control mechanisms. In view of bilingualism's potential link to local control mechanisms, we hypothesized that bilingualism would enhance reactivation benefits via adaptive trial-bytrial task-set reactivation. However, we expected that bilingualism would not confer benefits on local switch costs, which are thought to rely more on task-set reconfiguration than inhibition of proactive interference.

In addition, we included three control variables to control for any group differences in those costs: receptive vocabulary, as assessed by the Peabody Picture Verbal Test - Third Edition (Dunn \& Dunn, 1997); verbal cognitive flexibility, as assessed by the Remote Associates Test (Mednick, Mednick \& Mednick, 1964); and nonverbal fluid cognitive abilities, as assessed by the Trail Making Test - Part B (Arbuthnott \& Frank, 2000; Salthouse, 2011).

\section{Method}

\subsection{Participants}

Seventy-two undergraduates (males $=28$, aged 18-23 years) from Cornell University participated in exchange for extra course credit. Thirty-seven participants (male = 13) were bilinguals, and 35 were English monolinguals (male $=15$ ). To obtain a homogeneous group of Korean-English bilinguals, five bilinguals who spoke different language pairs (e.g., English and Chinese) were eliminated. Monolinguals were native English speakers and did not speak a second language. Monolinguals were Caucasian U.S. natives, and bilinguals were Korean Americans who had immigrated to the U.S. when they were young (see Table 1). Both groups contained more females than males, but the ratio of females to males in 
Table 1. Demographics, means, and standard deviations for cognitive tasks and bilinguals' self-reported language proficiency as a function of language group

\begin{tabular}{lllc}
\hline \hline & $\begin{array}{l}\text { Monolinguals } \\
(n=35)\end{array}$ & $\begin{array}{l}\text { Bilinguals } \\
(n=32)\end{array}$ & $t$ statistic \\
\hline $\begin{array}{l}\text { Age (in years) } \\
\text { Gender ratio (male: female) }\end{array}$ & $\begin{array}{l}20(1.3) \\
\text { Cognitive Measures }\end{array}$ & $\begin{array}{l}20.3(1.1) \\
13: 10\end{array}$ & -.67 \\
PPVT-III & $187.3(5.5)$ & $182(7.5)$ & $.82^{\mathrm{a}}$ \\
Remote Associates Test (RAT) & $9.1(3.83)$ & $6.03(4.3)$ & $3.18^{* *}$ \\
Trail Making Test (TMT-B) & $23.2(6.1)$ & $24.2(4.3)$ & $3.05^{* *}$ \\
Task-switching Error rates & & & -.74 \\
Last 2 trials in Block 1 & $5 \%$ & $7.8 \%$ & 1.12 \\
First 2 trials in Block 2 & $3 \%$ & $5 \%$ & .47 \\
Task-repeat trials in pure blocs & $5.4 \%$ & $5.3 \%$ & -.08 \\
Task-switch trials in mixed block & $10.5 \%$ & $10.5 \%$ & -.023 \\
Task-repeat trials in mixed block & $5 \%$ & $4 \%$ & -.862
\end{tabular}

\section{Language background}

Age at second language acquisition

Language preference ${ }^{b}$

Daily use of two languages ${ }^{\mathrm{c}}$

\section{Overall Proficiency}

Understanding (English: Korean)

Reading (English: Korean)

Writing (English: Korean)

Speaking (English: Korean)
$7.57(5.4)$

$38 \%: 38 \%: 24 \%$

45\%: $28 \%: 27 \%$

${ }^{\mathrm{a}} \mathrm{Chi}$-square statistics were used instead of $t$ statistics.

${ }^{\mathrm{b}}$ Language preference was rated using a 3 -point scale $(1=$ English, $2=$ Korean, and $3=$ both languages equally $)$.

${ }^{\mathrm{c}}$ Daily use of two languages was rated using a 3-point scale $(1=$ English, $2=$ Korean , and $3=$ both languages

equally frequently).

${ }^{*} p<.05,{ }^{* *} p<.01,{ }^{* * *} p<.001 . S D$ s are shown in parentheses.

the two groups was not statistically different, $\chi^{2}=.07$, $p=.82$.

\subsection{Design}

Block type (color, shape, mixed) was manipulated within participants as a function of bilingualism (monolinguals vs. bilinguals). Preliminary analyses did not show any effects of age, gender, or order-of-sorting rules (i.e., color first or shape first), so these variables were not included in reported analyses.

\subsection{Materials}

\section{Background measures}

The Peabody Picture Verbal Test - Third Edition (PPVT-III) was used as a standard measure to assess participants' receptive English vocabulary, which was the common language of instruction for both monolinguals and bilinguals in our sample. In the task, participants were shown a series of pages with four pictures on each and asked to specify the word the experimenter described.

The Remote Associates Test (RAT) was used to assess verbal cognitive flexibility compared to task switching, which measures nonverbal cognitive flexibility. On the RAT, a person is required to think of a solution word that is related to each of three other words - for instance, cadet, capsule, and ship (answer: space). In all, 21 RAT items of moderate difficulty were selected from the normative data of Bowden and Jung-Beeman (2003).

The Trail Making Test - Part B (TMT-B), which served as a measure of nonverbal fluid abilities (Salthouse, 2011), contains both numbers (1-13) and letters (AL). Participants were instructed to alternately connect the numbers and letters in sequential order (i.e., 1, A, 2, B, etc.), and given 2 min to complete the task. 
Performance was assessed in terms of the number of correct connections minus the number of incorrect connections.

\section{Dimensional Change Card Sort Task (DCCS)}

The DCCS was used to assess participants' task-switching performance. In the task, the target picture (i.e., either a blue truck or red star) appeared in the center of the screen (Diamond \& Kirkham, 2005; Yang et al., 2014). To reduce memory load, two reference pictures (e.g., a red truck and a blue star) appeared at the bottom of the screen, and the location of each corresponded to that of the specific response key on the keyboard (i.e., left or right) to press. Neither of the target pictures matched a reference picture on both color and shape. Participants were asked to sort the target by a cue word ("color" or "shape") that appeared on every trial between the two reference pictures at the bottom of the screen and specified the sorting criterion for that trial (see Figure 1).

\subsection{Procedure}

The RAT was administered first, followed by the computerized version of the DCCS and the paper-andpencil versions of the TMT-B and PPVT-III, along with a bilingualism questionnaire (age of acquisition, language preference, daily use of two languages, and overall proficiency in understanding, reading, writing, and speaking). The DCCS consisted of two pure blocks of a single sorting task (based on either color or shape), with a short pause between blocks, and one mixed block of two tasks - i.e., both color and shape tasks intermixed within the block. The order of the three blocks was fixed: two single-task pure blocks followed by a mixed block. Each of the two single-task pure blocks consisted of 15 trials of the same task, and the mixed block contained 30 trials of both task-switch and task-repeat (i.e., nonswitch) trials. In the mixed block, two sorting tasks alternated every two to three trials, resulting in 18 repetition trials (i.e., $\mathrm{AA}[\mathrm{A}]$ or $\mathrm{BB}[\mathrm{B}]$ ) and 12 switch trials (e.g., $\mathrm{AB}$ or $\mathrm{BA}$ ), with a task-probabilistic ratio of roughly 1.5:1. A task cue appeared on every trial, which rendered task switching unpredictable.

Each trial began with a cue that specified the trial's sorting criterion, followed by the target picture. The participant sorted the target picture according to the given sorting criterion (color or shape) by pressing the corresponding response key as accurately and quickly as possible. Because of overlapping stimulus-response mapping, the same target stimulus was associated with two possible responses (left or right key, depending on the sorting criterion). Throughout all trials, the cue-tostimulus interval (CSI) and the response-to-cue interval (RCI) were fixed at $500 \mathrm{~ms}$ and $800 \mathrm{~ms}$, respectively. The order of sorting criteria (color or shape) between the pure blocks and within the mixed block was counterbalanced across participants.

\section{Results}

\subsection{Verbal and cognitive measures}

A series of independent-samples $t$-tests was performed on the PPVT-III, RAT, and TMT-B. Consistent with the literature (e.g., Bialystok, Craik, Green \& Gollan, 2009), monolinguals showed significantly higher vocabulary scores as assessed by the PPVT-III $(M=187.3, S D=5.49)$ than bilinguals, $(M=182, S D=7.48), t(59)=5.3, p=$ .002 , Cohen's $d=.81$. This suggests that monolinguals have a larger receptive vocabulary than bilinguals.

On the RAT, monolinguals $(M=9.09, S D=3.84)$ also outperformed bilinguals $(M=6.03, S D=4.35)$, $t(65)=3.05, p=.003$, Cohen's $d=.74$, which suggests monolinguals' greater flexibility in a verbal domain. In view of a monolingual advantage in receptive vocabulary, this is presumably due to the task's reliance on verbal knowledge. Lastly, no group difference was found in scores for the TMT-B, which is regarded as an individualdifference measure of fluid cognitive abilities, $t(61)=$ $-.74, p=.46$ (Salthouse, 2011). Though the task seems to involve some aspects of nonverbal attentional switching, the TMT-B has been found to tap into fluid cognitive abilities (i.e., working memory capacity) rather than task-switching ability (Salthouse, 2011; Sanchez-Cubillo, Perianez, Adrover-Roig, Rodriguez-Sanchez, Rios-Lago, Tirapu \& Barcelo, 2009). Hence, the absence of group differences on the TMT-B indicates that the two groups were equivalent in fluid cognitive abilities. To summarize, monolinguals outperformed bilinguals in terms of lexical knowledge and verbal flexibility, but the two groups did not differ in terms of fluid cognitive abilities.

\subsection{Task-switching costs}

Incorrect trials were eliminated ( $7.3 \%$ of total trials), so that only correct trials were included in the analysis. Due to the small number of trials on the DCCS, variability among participants' means was high relative to the $S D$ in the distributions. Therefore, we followed the recommendation of Ratcliff (1993) and adopted the 1.5 SD cutoff method, which is known to have greater power than other methods for dealing with extreme RT outliers: Extreme RTs that were either greater than 1.5 SD above the mean or less than $200 \mathrm{~ms}$ (in all, $13.7 \%$ of total trials) were therefore discarded. ${ }^{1}$ Below,

\footnotetext{
1 Zhou and Krott (2016a) argue that data trimming can eliminate bilingual advantages. It is noteworthy, however, that their results cannot necessarily be generalized to include studies that use switching tasks; this is because they employed only nonverbal interference tasks
} 
we present separate analyses of RT data for each taskswitching cost.

\section{Single-task switch cost}

Following the literature (Diamond \& Kirkham, 2005; Yang et al., 2014), a single-task switch cost was computed from the two single-task pure blocks by comparing average RT on the last two trials in the first block with average RT on the first two trials in the second block. RT data were submitted to a repeated-measures mixed-factor ANOVA with Single-task switching (last two trials in Block 1 and first two trials in Block 2) and Bilingualism (monolinguals, bilinguals). We found a significant main effect of Single-task switching (i.e., single-task switch cost), as seen in the substantially elevated RTs when switching from the first to the second sorting criterion, $F(1,54)=6.74, p=.01$, $\eta_{\mathrm{p}}{ }^{2}=.11$ (Figure 2a). ${ }^{2}$ The main effect of Bilingualism, however, was not significant, $F(1,54)=.57, p=.45$. Importantly, an interaction between Single-task switching and Bilingualism approached significance, suggesting that bilingualism moderates single-task switch cost, $F(1,54)=$ $3.7, p=.06, \eta^{2}=.064$. Planned comparisons of paired $t$-tests to examine the presence of single-task switch cost (i.e., RT differences between the last two trials of Block 1 and the first two trials of Block 2) revealed that singletask switch cost was absent in bilinguals, $p>.67$, but not in monolinguals, $t(32)=-3.61, p=.001$, Cohen's $d=-.78$, which was corrected for dependence between means using Morris and DeShon's (2002) Equation 8; note that dependence between means should be corrected for in order to directly compare the effect sizes of a within-participant design to those of a between-participant design.

To further test the presence (absence) of single-task switch costs in monolinguals (bilinguals), we performed Bayesian paired $t$-tests, using Morey and Rouder's (Morey, Rouder \& Jamil, 2014) BayesFactor package for R. To compute Bayes factors, we set the scale parameter (r) of the prior in our Bayesian analysis to .707, as recommended. When we compared monolinguals' mean RTs on the last two trials of Block 1 with those on the first two trials of Block 2 (i.e., single-task switch costs), we obtained the scaled unit-information prior Bayes factor of

(e.g., the flanker effect), in which RT differences are mostly driven by the tail of RT distribution - which is captured by the tau parameter in ex-Gaussian analysis - rather than the typical mu parameter of the distribution (Calabria, Hernández, Martin \& Costa, 2011; Zhou \& Krott, 2016b)

2 Note that the degree of freedom for single-task switch cost differs from that of other task-switching costs. Different degrees of freedom for various task-switching costs occurred when trials that had been used to calculate cost were discarded, due to either errors or RT trimming for each individual, based on the individual's means and $S D$ s within each of the three blocks.
47.49, which indicates substantial support for the presence of monolinguals' single-task switch costs. In contrast, for the same comparison of bilinguals' mean RT differences, we obtained the scaled unit-information prior Bayes factor of 3.31, which offers little support for the presence of bilinguals' single-task switch costs. These results confirm that single-task switch costs are present for monolinguals, but not for bilinguals.

To examine the locus of the interaction effect, we also performed additional independent-samples $t$-tests to examine group differences on the last two trials of Block 1 (easy trials) and the first two trials of Block 2 (more difficult trials). We found that the two groups did not differ on mean RTs on the last two trials of Block 1, $\mathrm{M}_{\text {monolinguals }}=437, \mathrm{M}_{\text {bilinguals }}=484, t(61)=.393$, $p=.39$, Cohen's $d=.09$; however, group differences in mean RTs on the first two trials in Block 2 approached significance, $\mathrm{M}_{\text {monolinguals }}=553, \mathrm{M}_{\text {bilinguals }}=471$, $t(54)=1.84, p=.08$, Cohen's $d=.5$. The absence of group difference on relatively easier trials (i.e., the last two trials of Block 1) suggests that the significant Singletask switching $\mathrm{x}$ Bilingualism interaction is attributable to bilinguals' faster RTs on more difficult trials (i.e., the first two trials of Block 2) than on easier trials.

We also ran the same repeated-measures mixed-factor ANOVA on accuracy data, but did not find any significant effects (see Table 1). Follow-up analysis of independentsamples $t$-tests was performed on accuracy rates for the last two trials of Block 1 and the first two trials of the subsequent block, but we did not find significant effects, with all $p s>.26$.

\section{Local switch cost}

Local switch cost was obtained by computing mean RT difference between task-switch trials and task-repeat trials (i.e., nonswitch) within the mixed block (Rogers \& Monsell, 1995). RT data were submitted to a repeatedmeasures mixed-factor ANOVA with Bilingualism as a between-participant factor and Switching (task-switch trials, task-repeat trials) as a within-participant factor (Figure 2b). The main effect of Switching (i.e., local switch cost) was significant, $F(1,65)=88.1, p<.001$, $\eta^{2}=.58$, with significantly slower RTs on task-switch trials than on task-repeat trials. However, the main effect of Bilingualism, $F(1,65)=.84, p=.362$, and its interaction with Switching, $F(1,65)=1.12, p=.29$, were not significant, suggesting that both monolinguals and bilinguals experience substantial local switch costs.

We performed the same mixed-factor analysis on local switch costs in accuracy data, and found a significant main effect of Switching, $F(1,65)=36.9, p<.001$, indicating that task-switch trials were more error prone than taskrepeat trials. However, the main effect of Bilingualism and its interaction with Switching were not significant, all $p \mathrm{~s}>.51$. 
A. Single-task switch costs

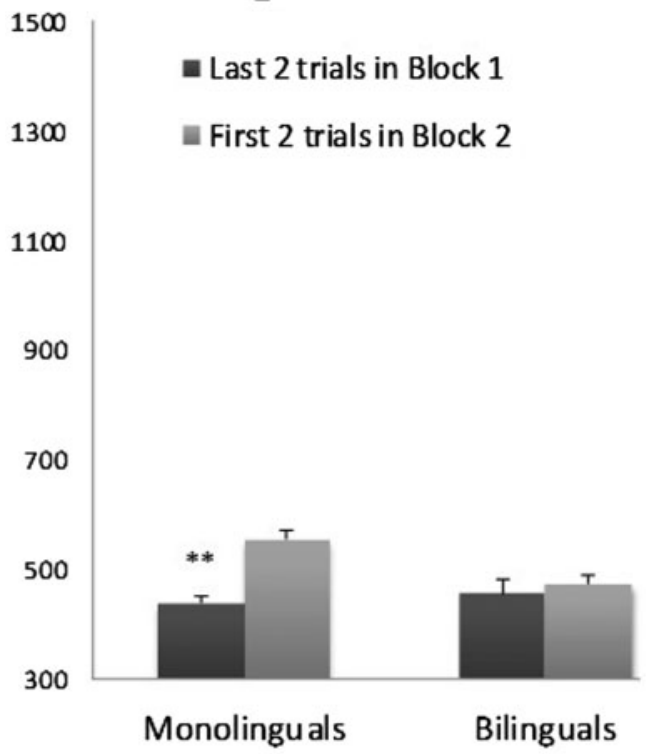

C. Mixing costs

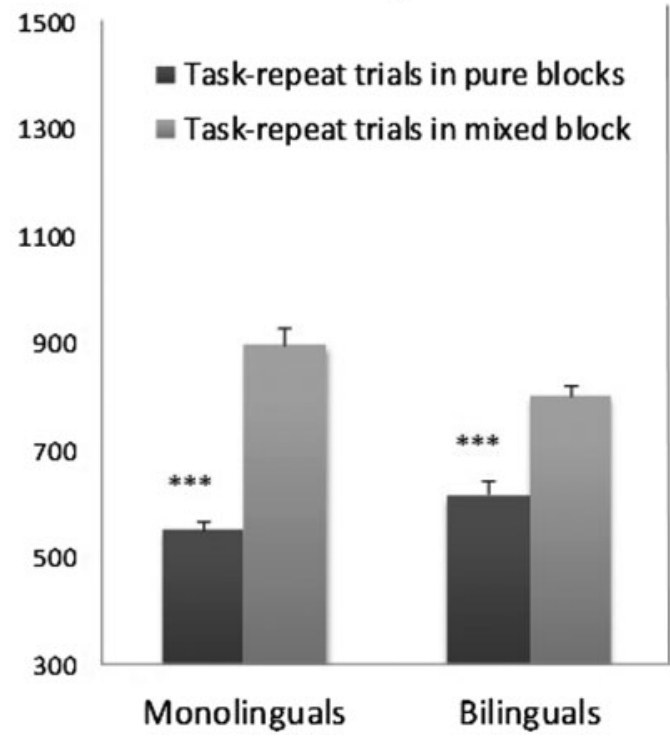

\section{B. Local-switch costs}

Task-repeat trials in mixed block

- Task-switch trials in mixed block

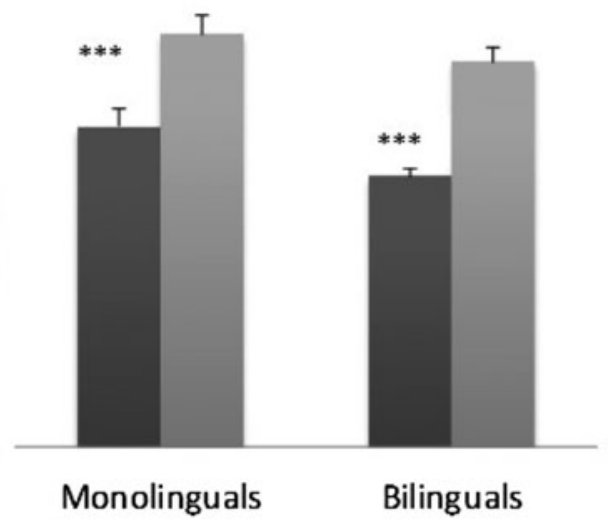

\section{Reactivation benefits}

- 1st repeat trials in mixed block

and repeat trials in mixed block

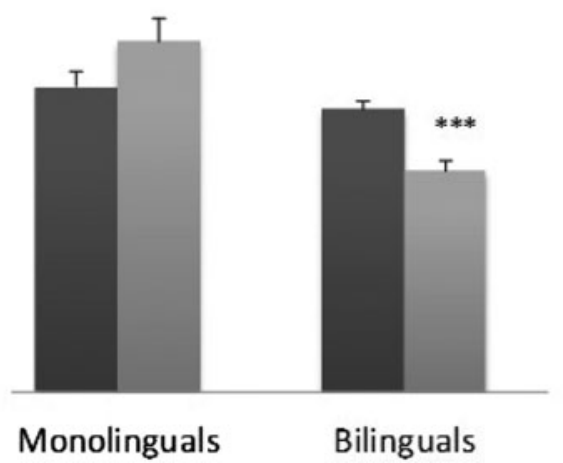

Figure 2. Task-switching costs as a function of language group.

\section{Mixing cost}

Mixing cost was computed by comparing mean RTs of task-repeat trials in the two single-task pure blocks with those of task-repeat trials in the mixed block. RT data were submitted to a similar ANOVA with Task mixing (taskrepeat trials in pure blocks, task-repeat trials in the mixed block) and Bilingualism. The main effect of Task mixing (i.e., mixing cost) was significant (Figure 2c), with poorer performance on the mixed block $(M=850 \mathrm{~ms})$ than on single-task pure blocks $(M=581 \mathrm{~ms}), F(1,65)=52.3, p<$ $.001, \eta_{\mathrm{p}}{ }^{2}=.45$. However, the main effect of Bilingualism was not significant, $F(1,65)=.01, p=.92$. Additionally, we found a significant interaction between Bilingualism and Task mixing, $F(1,65)=4.63, p=.035, \eta_{\mathrm{p}}{ }^{2}=.07$. Follow-up analysis of paired $t$-tests to test the presence of mixing costs revealed that both monolinguals and bilinguals experienced substantial mixing costs, but they were more pronounced in monolinguals, $t(34)=6.08, p<$ .001 , Cohen's $d=1.17$, than bilinguals, $t(31)=4.11, p<$ .001 , Cohen's $d=.73$. We also examined the locus of the interaction effect by performing additional independentsamples $t$-tests to examine group differences on 
task-repeat trials in pure blocks (easy trials) and those in the mixed block (more difficult trials). We found no significant differences on either easier or more difficult trials: On easier trials (i.e., task-repeat trials in pure blocks), $\mathrm{M}_{\text {monolinguals }}=550, \mathrm{M}_{\text {bilinguals }}=614, t(65)=$ $-1.09, p=.28$, Cohen's $d=-.26$; on more difficult trials (i.e., task-repeat trials in the mixed block), $\mathrm{M}_{\text {monolinguals }}=$ $910, \mathrm{M}_{\text {bilinguals }}=799, t(65)=1.39, p=.16$, Cohen's $d=.34$. In light of these results, monolinguals' relatively faster RTs on easier trials and slower RTs on difficult trials could have played an instrumental role in our finding of a significant interaction effect for mixing cost.

We also ran the same ANOVA model on mixing costs in accuracy data and found similar patterns. That is, the main effects of Task-mixing and Bilingualism were not significant, $F(1,65)=2.71, p=.11$ and $F(1,65)=.56$, $p=.35$, but we found a marginally significant interaction between Task-mixing and Bilingualism, $F(1,65)=2.86$, $p=.09$, indicating bilinguals' higher accuracy rates associated with mixing cost. When follow-up analyses of paired $t$-tests were performed to examine mixing costs within each group, we found that mixing cost in accuracy was absent in bilinguals, $p=.97$, but not in monolinguals, $p=.06$.

\section{Reactivation benefit}

We operationalized reactivation benefit in mixed blocks by calculating RT drops between first-repetition trials and second-repetition trials. Cues in our DCCS were randomly presented on every trial, such that participants were unable to predict which task would be performed and had to reactivate the same task set in a series of taskrepeat trials. This ensured that subsequent repetition trials would still be challenging, due to the cognitive resources required not only for constant reactivation, but also to address unpredictability. Hence, greater RT facilitation on subsequent repeat trials than on first-repeat trials should indicate the magnitude of benefits for reactivating the same task set in the midst of unpredictability. This is accomplished via more adaptive reactive control abilities at a local level, which involve swift and successful reactivation in response to current demand, efficient monitoring of task sets, mental preparation, etc. (De Baene, Kühn \& Brass, 2012). Note that our reactivation benefit differs conceptually from Hernández et al.'s (2013) restart cost. In their study, the same task set was repeatedly performed in a predicted succession. Therefore, the cost for reactivating the same task set on subsequent trials was reduced to a minimum, because a task set employed in a previous trial could be used again in a subsequent trial.

To approximate reactivation benefits - i.e., RT drops between first-repetition trials and second-repetition trials - we defined each trial in the mixed block relative to its position: P1 (Position $1=$ switch trial); P2 (Position 2 = first-repeat trial); and P3 (Position $3=$ second-repeat trial). The reactivation benefit was computed in the mixed block by subtracting mean RTs of second-repeat trials (P3) from those of first-repeat trials (P2).

When RT data were submitted to a similar ANOVA with Reactivation (P2, P3) and Bilingualism, we found that the main effect of Reactivation was not significant, $F(1,65)=.202, p=.65$, which indicates that the mean RTs for P2 and P3 were not different; presumably, this is because repetition occurred unpredictably. Notably, however, the main effect of Bilingualism approached significance, $F(1,65)=3.272, p=.07$, indicating that bilinguals were faster than monolinguals in those two task-repeat trials. Moreover, the interaction between Reactivation and Bilingualism was also significant, $F(1,65)=9.91, p=.002, \eta^{2}=.13$ (Figure 2d). Planned comparisons of paired $t$-tests showed significant RT drops from P2 to P3 in bilinguals $\left(M_{\mathrm{p} 2}=827.2, M_{\mathrm{p} 3}=713.8\right)$, $t(31)=4.09, p<.001$, but not monolinguals $\left(M_{\mathrm{p} 2}=\right.$ 869.7, $\left.M_{\mathrm{p} 3}=954.8\right), p=.13$.

Furthermore, when we examined the locus of the interaction effect by performing additional independentsamples $t$-tests, we found that the two groups did not differ on first task-repeat trials $(\mathrm{P} 2), t(65)=.64, p=.54$, Cohen's $d=.15$. However, they differed significantly on subsequently repeated trials $\left(\mathrm{P} 3 ; \mathrm{M}_{\text {bilinguals }}=713.8\right.$, $\left.\mathrm{M}_{\text {monolinguals }}=954.8 \mathrm{~ms}\right), t(65)=2.43, p=.018$, Cohen's $d=.60$. This suggests that the Bilingualism $\mathrm{x}$ Task-mixing interaction effect - which supports bilingual advantages in reactivation benefits - is attributable to bilinguals' faster RTs on second task-repeat trials, which are relatively more difficult than first task-repeat trials due to the irregular and unpredictable nature of subsequent repetition. Note that when task repetition occurs randomly without any predictable pattern, subsequent repetition is likely to be either more difficult than or equally challenging as the immediately preceding repetition. Given this, mean RTs on the second task-repeat trials could be faster than those on the first task-repeat trials only when the participant engaged in more adaptive and flexible task-set reactivation via efficient monitoring and evaluation of switching activities. Hence, bilinguals' faster RTs on the second task-repeat trials imply that bilinguals perform task-set reactivation more adaptively and flexibly than monolinguals, despite the unpredictable nature of task repetition.

\section{Cue-priming effect}

The DCCS is based on 1:1 cue-task mapping (i.e., one cue per task), in which task switch and cue switch always co-occur. Therefore, it is possible that basic cue-priming processes may underlie any advantages in task-switching performance (for a review, see Logan \& Bundesen, 2003). Specifically, a response adjustment across task-repeat trials can be driven by two mechanisms. First, it can be due to efficient adaptation to abstract task-set reactivation, 
which engages cognitive control (De Baene et al., 2012). Second, it can be due to a mere visual adaptation to the same task cue that repeatedly occurs in two consecutive trials, i.e., cue-priming effects (e.g., Logan \& Bundesen, 2003). Although the latter view is controversial (De Baene et al., 2012; Schneider \& Logan, 2011), it is important to examine whether bilingual advantages in various markers for task-switching performance can be attributed to basic cue priming instead of complex control processes.

To assess the impact of the cue-priming effect that underlies cue repetition, we examined whether bilingualism systematically influenced the temporal pattern of RT facilitations within pure blocks, in which a single cue was repeatedly presented throughout; this allows cue-encoding benefits (e.g., Logan \& Bundesen, 2003) to be established through priming processes. Thus, we approximated the cue-priming effect by splitting the trials of each pure block into three bins spanning five trials each and examined RT facilitation across the three bins, in which the same task cue appeared repeatedly. If cue-priming effects moderated bilingual advantage in task switching, we should see a significant threeway interaction between Bilingualism, Order of pure blocks, and Bins, since this implies that bilinguals and monolinguals are affected differently by the cue-priming effect signaled by an interaction between Order of pure blocks and Bins.

To test this, we submitted RT data to a 2 (Bilinguals, monolinguals) $\times 2$ (Order of pure blocks: block 1, block 2) $\times 3$ (Bins: $\mathrm{B}_{1}, \mathrm{~B}_{2}, \mathrm{~B}_{3}$ ) mixed-factor ANOVA and found significant main effects of Order of pure blocks, $F(1,60)=22.8, p<.001$, and Bins, $F(2$, $120)=37.2, p<.001$, as well as an interaction effect between the two, $F(2,120)=18.6, p<.001$, which indicates the presence of RT facilitation in response to repeated presentation of the same cue. However, the threeway Order $\mathrm{x}$ Bin $\mathrm{x}$ Bilingualism interaction was not significant, $p>.45$, suggesting that both monolinguals and bilinguals were similarly affected by repeated cues. Therefore, our findings of bilingual benefits in taskswitching performance cannot be attributed to mere cue priming. In line with De Baene et al.'s (2012) contention that repeating the same task set recruits the brain regions involved in cognitive control (i.e., the prefrontal and parietal cortices) - which is different from low-level visual adaptation to the task cue (e.g., Logan \& Bundesen, 2003) - our findings support bilinguals' more flexible and adaptive control.

\section{General Discussion}

Using the DCCS, we obtained the following key results, despite bilinguals' poorer lexical knowledge and flexibility in the verbal domain. First, single-task switch costs were absent among bilinguals, but not among monolinguals; this indicates a bilingual advantage in flexible switching that largely taps into global proactive control. Second, reactivation benefits were significant among bilinguals, but were absent among monolinguals; this suggests bilinguals' adaptive task-set reactivation at a local-control level, despite unpredictable trialby-trial variations. Third, although both monolinguals and bilinguals experienced substantial mixing costs, bilinguals had less pronounced mixing costs than monolinguals via more efficient monitoring at a globalcontrol level. Lastly, we found no group differences in local switch costs attributable to task-set reconfiguration at a local-control level. Considering that monolinguals and bilinguals were similarly affected by cue-priming effects, our finding of bilingual advantages in single-task switch costs, mixing costs, and reactivation benefits can be attributed to differences in control processing - i.e., proactive control and monitoring at a global-control level and task-set reactivation at a local-control level.

It is important to address why our bilingual participants showed advantages in single-task switch costs but not in local switch costs. Although these two types of switch costs entail switching between two tasks and appear to be very similar, they engage somewhat distinct control processing. Specifically, single-task switch cost, which occurs between two pure blocks, imposes a relatively greater load on global proactive interference than local task-set reconfiguration. In contrast, local switch cost - which occurs when the two tasks rapidly alternate within the mixed block - imposes a greater load on task-set reconfiguration. Hence, our finding of bilingual advantages in single-task switch costs may be attributable in large part to the extent to which a given task implicates inhibition of proactive interference at a global level.

Although we have not observed any bilingual advantages in local switch costs, it is noteworthy that our results do not necessarily indicate that bilingualism has no effect on task-set reconfiguration. According to the adaptive-control hypothesis (Green \& Abutalebi, 2013), different types of language switching in various interactional contexts of bilinguals' conversational exchanges may impose different demands on cognitive control. Therefore, a qualitatively different experience of bilinguals' language switching may play a more important role in modulating local switch costs via efficient task-set reconfiguration (Hartanto \& Yang, 2016).

It is worth mentioning that some studies caution against interpretation of a typical Bilingualism $\mathrm{x}$ Trial type interaction that is mainly driven by a monolingual advantage on easy trials in either a flanker task (e.g., congruent trials as opposed to incongruent trials) or a switching (e.g., task-repeat trials as opposed to taskswitch trials) task (see Paap, Johnson \& Sawi, 2015, and Wagenmackers, 2015; for different interpretations, see Linck, 2015, and Linck, Schwieter \& Sunderman, 2012). 
When we tested this possibility, we found little evidence that bilingual advantages in single-task switch costs and reactivation benefits were driven by a monolingual advantage on easy trials. In fact, we found that for mixing cost, a significant Bilingual x Task-mixing (i.e., trial types) interaction effect could be attributed to monolinguals' relative advantage on easier trials (i.e., task-repeat trials in pure blocks) and bilinguals' relative advantage on difficult trials (i.e., task-switch trials in the mixed block). In light of this, it is notable that Linck (2015) has a different perspective on the lack of bilingual advantages on easy trials (see also Linck et al., 2012). According to Linck et al. (2012), inhibitory control may influence both more demanding and less demanding trials, because even less demanding trials may still require efficient disengagement from inhibitory control mechanisms. Linck et al. also suggest that the absence of bilingual advantages on easy trials may be due to a different response strategy, which causes bilinguals' conflict-monitoring system to take less advantage of facilitation from repeated trials, which do not involve high monitoring. Therefore, follow-up tests of a Bilingualism $\mathrm{x}$ Trial interaction should be interpreted with caution.

Given that our reactivation benefit was computed similarly to Hernández et al.'s (2013) restart cost, it is important to understand the conceptual differences between our reactivation benefit and restart cost. Specifically, in Hernández et al.'s intermittent task-cue paradigm, participants were presented with intermittent cues ("switch" or "repeat") every four to eight trials. Once the repeat cue appeared, participants were able to easily predict the relevant task set to reactivate on the first and second trials that were used to compute restart cost. Hence, restart cost - which refers to mean RT difference between the first- and second-repetition trials - reflects the cost associated with predictable taskset reactivation. In contrast, cues in the DCCS were randomly presented in every trial, such that participants were unable to predict which task to reactivate on any given trial; therefore, the task-relevant set should have been reactivated unpredictably for each and every trial. In view of this difference, RT drops between the first- and second-repetition trials in the mixed blocks of the DCCS should indicate the magnitude of savings associated with unpredictable reactivation. Hence, bilinguals' substantial reactivation benefits in an unpredictable context should reflect their engagement of adaptive and effective control mechanisms to reactivate the relevant task set.

Some may argue that motivation could have played a role in group differences in mixing costs. Although we do not have any direct evidence for this effect, it seems less plausible, at least in our study, for the following reasons. First, given that motivation usually facilitates RTs in a context in which a participant's response speed is highly stressed, if bilinguals were motivated to perform the task, their overall RTs should have been faster than those of monolinguals. However, the two groups' overall mean RTs did not differ $\left(\mathrm{M}_{\text {monolinguals }}=807, \mathrm{M}_{\text {bilinguals }}=811\right.$, $t(65)=-.06, p=.96)$. Moreover, motivation does not explain why bilingualism selectively facilitated RTs on task-repeat trials over those on switch trials, which had been presented in the same block; note that no bilingual advantage in switch costs was found. Second, our DCCS task employed a small number of trials (30 trials in the pure blocks and 30 trials in the mixed block), such that the total duration of the switching task was only about $6 \mathrm{~min}$. Considering this, motivation does not sufficiently explain why monolinguals' motivation suddenly declined in the mixed block, while bilinguals' motivation did not. Relatedly, given that task-switch trials alternated with task-repeat trials in a fast and unpredictable manner, it is not plausible that motivation fluctuated so rapidly every few seconds within the same mixed block, favoring one type of trial over the other; if bilinguals were more motivated, their better regulation to remain motivated throughout the mixed block would also reflect their advantage in cognitive control. Lastly, there was no apparent reason for bilinguals to be more motivated to do better on given tasks than monolinguals, because the language-background questionnaire was administered at the end of the study. Thus, neither group was aware of our goal in the study. For these reasons, it is difficult to argue that significant group differences in task switching can be attributed to bilinguals' greater motivation.

Our study is not without drawbacks. First, due to the practical difficulties of recruiting Korean-English bilinguals from immigrant families, we acknowledge that our sample size $\left(N_{\text {bilinguals }}=32 ; N_{\text {monolinguals }}=35\right)$ was relatively small; further studies with larger samples should be performed to replicate our findings (Paap et al., 2015). Second, we employed a small number of trials to maintain a certain degree of task novelty to prevent potential practice effects and increase demand for executive processing throughout the task. Moreover, given that task novelty is regarded as an important factor that influences cognitive control via heightened cognitive load (e.g., Gray, 2001), task novelty is considered to be critical for improving the task's ability to capture potential group differences in cognitive control (Costa et al., 2009). Although we acknowledge that the small number of trials could have affected reliability for single-task switch costs that involved only four trials, past studies in the taskswitching literature have demonstrated the existence of single-task switch costs. For example, Poljac, De Haan, and Van Galen (2006) found significantly slower RTs for the first trial of the subsequent block - which consisted of seven trials of a shape task - than for the last trial in the immediately preceding block (seven trials of a color task). Single-task switch costs have also reliably 
been demonstrated in other studies that used a similar DCCS paradigm (Diamond \& Kirkham, 2005; Yang \& Yang, 2014). Also, the effect size associated with singletask switch costs was considerable (e.g., Cohen's $d=1.31$ in Diamond \& Kirkham, 2005; our Cohen's $d$ was .78), which indicates that RT differences between the last two trials in Block 1 and the first two trials in Block 2 were indeed substantial.

Third, another limitation is that our bilingual participants were not matched to their monolingual counterparts in terms of ethnicity, culture, or immigration status; our Korean-English bilinguals were from Korean immigrant families in the U.S., and monolinguals were from nonimmigrant Caucasian families in the same region. Despite these differences, however, we can still assume that our participants were similar, because they were recruited from the same private institution, which charges high tuition and is highly selective in terms of students' academic qualifications. Inferring from this background, our participants were likely from upperor middle-class families and possessed the academic ability required to satisfy the school's rigorous admission standards, regardless of background differences (e.g., ethnicity or SES).

In addition, our participants' cultural backgrounds are not entirely different; our bilinguals were affiliated with both Korean and Western culture, since - like their monolingual counterparts - they were raised and educated in the U.S. Moreover, evidence in the literature is lacking to support significant effects of the abovementioned factors on the cognitive consequences of bilingualism; some evidence suggests that they may not play a substantial role in bilingual advantages in executive functions. For instance, Kirk, Scott-Brown, and Kempe (2014) found that advantage in executive control is not related to differences in culture, ethnicity, or immigrant status. Similarly, Yang, Yang, and Lust (2011) suggest that the beneficial effect of bilingualism extends above and beyond the effect of culture. Even the stark differences in the A1 allele - a gene that has been shown to influence task switching - between Hispanics and Caucasians has been attributed to bilingualism instead of ethnicity (Hernandez, Greene, Vaughn, Francis \& Grigorenko, 2015). Likewise, given that immigration status is linked to SES (e.g., Morton \& Harper, 2007), studies have found that bilingualism benefits executive control despite bilinguals' low SES (see Engel de Abreu, Cruz-Santos, Tourinho, Martin \& Bialystok, 2012). Given the weight of supporting evidence, therefore, it is doubtful that our findings are substantially confounded by ethnicity, culture, or immigration status. More research is warranted to examine whether and how these factors significantly influence bilingual advantages.

Lastly, our study was not designed to identify the specific interactional context of our bilingual participants.
Although we measured bilinguals' daily use of two languages (English vs. Korean), this was not sufficient to determine bilinguals' interactional context, because it does not accurately capture how bilinguals use their languages and in what contexts. Because of this constraint, it is not possible to examine the relation of bilinguals' interactional contexts to different markers of language switching on the DCCS. However, given that the majority of our Korean-English bilinguals speak English at school and Korean at home or in the community, our bilingual participants are likely to be single-context bilinguals who speak only one language in one environment (e.g., mother tongue at home and English at school) rather than dualcontext bilinguals who use two languages within the same context (e.g., both Korean and English at home). Our findings that Korean-English bilinguals did not differ from monolinguals in either mixing costs or local switch costs are consistent with the adaptive control hypothesis (Green \& Abutalebi, 2013), which suggests that bilingual advantages in switch costs will be pronounced for dualcontext bilinguals, but not so much for single-context bilinguals (Hartanto \& Yang, 2016).

On the whole, our study is unique, not only because of the methodological strength afforded by use of the DCCS, but also because of our homogeneous bilingual group (i.e., Korean-English). A widespread assumption in the bilingualism literature is that bilingual effects are reliable across different language combinations. However, this assumption has recently been questioned. Specifically, Coderre and van Heuven (2014) demonstrate the importance of the two languages' script similarity (e.g., German-English vs. Arabic-English) for domaingeneral executive control (for a critique, see Paap, Darrow, Dalibar \& Johnson, 2014). Given the markedly different orthographies of English and Korean, however, our findings suggest that the script dissimilarity of bilinguals' language pair may also affect various facets of cognitive control - e.g., inhibitory control, updating, and switching (Yang, Yang \& Hartanto, 2016).

In addition, since English and Korean differ in terms of sentence structure and morphology (i.e., word structure), it is possible that not only script dissimilarity but also other linguistic aspects of Korean may have contributed to Korean-English advantages in task switching. For instance, Korean has a subject-object-verb word order that is distinct from the subject-verb-object word order in English. This difference in sentence structure may place greater demands on cognitive control, especially when Korean-English bilinguals alternate between languages, and therefore lead to substantial benefits in task-switching abilities. Future studies are warranted to determine how script similarity (or other language-based characteristics) modulates bilingual advantages in various aspects of cognitive control. 
In summary, our study demonstrates bilinguals' enhanced performance in single-task switch costs and reactivation benefits and their relatively small benefits in mixing costs. Given that bilingualism affects the monitoring processes involved in executive control (e.g., Costa et al., 2009), bilingual advantages in singletask switch costs and mixing costs can be attributed to facility in global control processes that require proactive control and careful monitoring of two competing task sets in the face of interference in a mixed block (De Baene et al., 2012). Moreover, our finding of bilinguals' reactivation benefits supports bilingual advantages in local control processing, especially when efficient adaptation to abstract task-set reactivation is necessary due to the unpredictable nature of task repetition. 
Appendix 1. Summary of studies examining bilingual advantages using a Task-switching Paradigm (Task-cuing Paradigm)

\begin{tabular}{|c|c|c|c|c|c|}
\hline Study & Participants & Mean age & Task & Number of trials & Task-switching outcome \\
\hline Bialystok (1999) & $\begin{array}{l}\text { Bilinguals }(N=30) \\
\text { Monolinguals }(N=30)\end{array}$ & Children (4.9) & DCCS & $\begin{array}{l}20 \text { trials }(10 \text { pre-switch } \\
\text { trials } \& 10 \text { post-switch } \\
\text { trials })\end{array}$ & $\begin{array}{l}\text { Bilinguals' post-switch } \\
\text { advantage in accuracy (i.e., } \\
\text { single-task switch cost) }\end{array}$ \\
\hline $\begin{array}{l}\text { Bialystok \& Martin } \\
\text { (2004) }\end{array}$ & $\begin{array}{l}\text { Chinese-English bilinguals }(N=31) \\
\text { English monolinguals }(N=36)\end{array}$ & Children (4.9) & $\begin{array}{l}\text { Computerized } \\
\text { DCCS }\end{array}$ & $\begin{array}{l}80 \text { trials ( } 20 \text { non-switch } \\
\text { trials, } 30 \text { pre-switch } \\
\text { trials, \& } 30 \text { post-switch } \\
\text { trials) }\end{array}$ & $\begin{array}{l}\text { Bilinguals' post-switch } \\
\text { advantage in accuracy (i.e., } \\
\text { single-task switch cost) }\end{array}$ \\
\hline $\begin{array}{l}\text { Carlson \& Meltzoff } \\
\text { (2008) }\end{array}$ & $\begin{array}{l}\text { Spanish-English bilinguals }(N=12) \\
\text { Language immersion children }(N=21) \\
\text { Monolinguals }(N=17)\end{array}$ & 6.0 & Advanced DCCS & $\begin{array}{l}20 \text { trials ( } 16 \text { shape trials } \& \\
4 \text { color trials) }\end{array}$ & $\begin{array}{l}\text { Bilinguals' post-switch } \\
\text { advantage in accuracy (i.e., } \\
\text { single-task switch cost) }\end{array}$ \\
\hline Garbin et al. (2010) & $\begin{array}{l}\text { Bilinguals }(N=19) \\
\quad \text { Monolinguals }(N=21)\end{array}$ & $\begin{array}{l}\text { Young adults } \\
\text { (20.9) }\end{array}$ & $\begin{array}{l}\text { Color-shape } \\
\text { switching task }\end{array}$ & $\begin{array}{l}60 \text { trials ( } 30 \text { mixed-switch } \\
\quad \& 30 \text { mixed-repeat) }\end{array}$ & $\begin{array}{l}\text { Bilinguals' switch-cost } \\
\text { advantage }\end{array}$ \\
\hline $\begin{array}{l}\text { Prior \& MacWhinney } \\
\text { (2010) }\end{array}$ & $\begin{array}{l}\text { Bilinguals }(N=47) \\
\quad \text { Monolinguals }(N=45)\end{array}$ & $\begin{array}{l}\text { Young adults } \\
\text { (19.1) }\end{array}$ & $\begin{array}{l}\text { Color-shape } \\
\text { switching task }\end{array}$ & $\begin{array}{l}288 \text { trials ( } 144 \text { pure-repeat, } \\
72 \text { mixed-switch \& } 72 \\
\text { mixed-repeat) sandwich } \\
\text { design }\end{array}$ & $\begin{array}{l}\text { Bilinguals' switch-cost } \\
\text { advantage }\end{array}$ \\
\hline Prior \& Gollan (2011) & $\begin{array}{l}\text { Spanish-English bilinguals }(N=41) \\
\text { Mandarin-English bilinguals }(N=43) \\
\text { Monolinguals }(N=47)\end{array}$ & $\begin{array}{l}\text { Young adults } \\
\text { (19.9) }\end{array}$ & $\begin{array}{l}\text { Color-shape } \\
\text { switching task }\end{array}$ & $\begin{array}{l}288 \text { trials ( } 144 \text { pure-repeat, } \\
72 \text { mixed-switch } \& 72 \\
\text { mixed-repeat) }\end{array}$ & $\begin{array}{l}\text { Spanish-English bilinguals' } \\
\text { relative advantage in switch } \\
\text { cost among (but not in } \\
\text { Chinese-English bilinguals) } \\
\text { after controlling for parents' } \\
\text { educational level }\end{array}$ \\
\hline $\begin{array}{l}\text { Soveri, } \\
\text { Rodriguez-Fornells } \\
\text { \& Laine (2011) }\end{array}$ & Finnish-Swedish bilinguals $(N=38)$ & Older adults (52.8) & $\begin{array}{l}\text { Number-letter } \\
\text { switching task }\end{array}$ & $\begin{array}{l}144 \text { trials ( } 64 \text { pure-repeat, } \\
32 \text { mixed-switch \& } 48 \\
\text { mixed-repeat) }\end{array}$ & $\begin{array}{l}\text { Mixing-cost advantage in } \\
\text { frequent language switching } \\
\text { bilinguals }\end{array}$ \\
\hline $\begin{array}{l}\text { Barac \& Bialystok } \\
\text { (2012) }\end{array}$ & $\begin{array}{l}\text { Chinese-English bilinguals }(N=30) \\
\text { French-English bilinguals } \\
(N=28) \\
\text { Spanish-English bilinguals } \\
(N=20) \\
\text { English monolingual }(N=26)\end{array}$ & Children (6.1) & $\begin{array}{l}\text { Color-shape task } \\
\text { switching }\end{array}$ & $\begin{array}{l}200 \text { trials ( } 50 \text { pure-repeat } \\
\text { trials \& } 150 \text { trials with } \\
50 \% \text { of switch \& } 50 \% \text { of } \\
\text { repeat) }\end{array}$ & $\begin{array}{l}\text { Bilinguals' mixing-cost } \\
\text { advantage }\end{array}$ \\
\hline
\end{tabular}


Appendix 1. Continued.

\begin{tabular}{|c|c|c|c|c|c|}
\hline Study & Participants & Mean age & Task & Number of trials & Task-switching outcome \\
\hline $\begin{array}{l}\text { Hernández et al. } \\
\text { (2013; experiment } \\
\text { 3) }\end{array}$ & $\begin{array}{l}\text { Bilinguals }(N=38) \\
\text { Monolinguals }(N=39)\end{array}$ & $\begin{array}{l}\text { Young adults } \\
\text { (19.9) }\end{array}$ & $\begin{array}{l}\text { Color-shape } \\
\text { switching task }\end{array}$ & $\begin{array}{l}288 \text { trials ( } 144 \text { pure-repeat, } \\
72 \text { mixed-switch \& } 72 \\
\text { mixed-repeat) }\end{array}$ & No bilingual advantages \\
\hline $\begin{array}{l}\text { Paap \& Greenberg } \\
\text { (2013) }\end{array}$ & $\begin{array}{l}\text { Bilinguals }(N=109) \\
\text { Monolinguals }(N=144)\end{array}$ & Young adults (NA) & $\begin{array}{l}\text { Color-shape } \\
\text { switching task }\end{array}$ & $\begin{array}{l}288 \text { trials (144 pure-repeat, } \\
72 \text { mixed-switch \& } 72 \\
\text { mixed-repeat) }\end{array}$ & No bilingual advantages \\
\hline $\begin{array}{l}\text { Gold, Kim, Johnson, } \\
\text { Kryscio \& Smith } \\
\text { (2013; experiment } \\
\text { 1) }\end{array}$ & $\begin{array}{l}\text { Older adult bilinguals } \\
\qquad(N=15) \\
\text { Older adult monolinguals } \\
(N=15)\end{array}$ & Older adults (63.7) & $\begin{array}{l}\text { Color-shape } \\
\text { switching task }\end{array}$ & $\begin{array}{l}240 \text { trials ( } 80 \text { pure-repeat, } \\
80 \text { mixed-switch, } 80 \\
\text { mixed-repeat) }\end{array}$ & $\begin{array}{l}\text { Bilinguals' mixing-cost } \\
\text { advantage }\end{array}$ \\
\hline $\begin{array}{l}\text { Gold et al. (2013; } \\
\text { experiment 2) }\end{array}$ & $\begin{array}{l}\text { Older adult bilinguals }(N=20) \\
\text { Younger adult bilinguals } \\
(N=20) \\
\text { Older adult monolinguals }(N=20) \\
\text { Young adult bilinguals } \\
(N=20)\end{array}$ & $\begin{array}{l}\text { Young adults } \\
\text { (31.9) and Older } \\
\text { adults (64.2) }\end{array}$ & $\begin{array}{l}\text { Color-shape } \\
\text { switching task }\end{array}$ & $\begin{array}{l}240 \text { trials ( } 80 \text { pure-repeat, } \\
80 \text { mixed-switch, } 80 \\
\text { mixed-repeat) }\end{array}$ & $\begin{array}{l}\text { No bilingual advantages } \\
\quad(p=.056 \text { trend toward } \\
\text { older bilinguals' } \\
\text { mixing-cost advantage) }\end{array}$ \\
\hline Paap \& Sawi (2014) & $\begin{array}{l}\text { Bilinguals }(N=58) \\
\text { Monolinguals }(N=62)\end{array}$ & $\begin{array}{l}\text { Young adults } \\
\quad(24.6)\end{array}$ & $\begin{array}{l}\text { Color-shape } \\
\text { switching task }\end{array}$ & $\begin{array}{l}288 \text { trials ( } 144 \text { pure-repeat, } \\
72 \text { mixed-switch \& } 72 \\
\text { mixed-repeat) }\end{array}$ & No bilingual advantages \\
\hline $\begin{array}{l}\text { Wiseheart, } \\
\text { Viswanathan \& } \\
\text { Bialystok (2016) }\end{array}$ & $\begin{array}{l}\text { Bilinguals }(N=31) \\
\text { Monolinguals }(N=37)\end{array}$ & $\begin{array}{l}\text { Young adults } \\
\text { (19.1) }\end{array}$ & $\begin{array}{l}\text { Color-shape } \\
\text { switching task }\end{array}$ & $\begin{array}{l}150 \text { trials ( } 50 \text { pure-repeat, } \\
50 \text { mixed-switch \& } 50 \\
\text { mixed-repeat) }\end{array}$ & $\begin{array}{l}\text { Bilinguals' mixing-cost } \\
\text { advantage }\end{array}$ \\
\hline $\begin{array}{l}\text { Mor, } \\
\text { Yitzhaki-Amsalem } \\
\text { \& Prior (2015) }\end{array}$ & $\begin{array}{l}\text { Bilinguals with ADHD } \\
(N=20) \\
\text { Bilinguals control }(N=20) \\
\text { Monolingual with ADHD } \\
(N=20) \\
\text { Monolingual control }(N=20)\end{array}$ & $\begin{array}{l}\text { Young adults } \\
\text { (24.6) }\end{array}$ & $\begin{array}{l}\text { Color-shape } \\
\text { switching task }\end{array}$ & $\begin{array}{l}288 \text { trials (144 pure-repeat, } \\
72 \text { mixed-switch \& } 72 \\
\text { mixed-repeat) sandwich } \\
\text { design }\end{array}$ & No bilingual advantages \\
\hline
\end{tabular}


Appendix 1. Continued.

\begin{tabular}{|c|c|c|c|c|c|}
\hline Study & Participants & Mean age & Task & Number of trials & Task-switching outcome \\
\hline $\begin{array}{l}\text { Qu, Low, Zhang, Li \& } \\
\text { Zelazo (2016; ScAc } \\
\text { condition) })^{3}\end{array}$ & $\begin{array}{l}\text { Chinese-English bilinguals } \\
\qquad(N=32) \\
\text { Chinese monolinguals }(N=32)\end{array}$ & $\begin{array}{l}\text { Young adults } \\
(21.1)\end{array}$ & $\begin{array}{l}\text { Computerized } \\
\text { DCCS }\end{array}$ & $\begin{array}{l}118 \text { trials ( } 40 \text { pure-repeat, } \\
10 \text { mixed-switch \& } 68 \\
\text { mixed-repeat) }\end{array}$ & $\begin{array}{l}\text { Bilinguals' switch-cost } \\
\text { advantage and } \\
\text { monolinguals' mixing-cost } \\
\text { advantage }\end{array}$ \\
\hline $\begin{array}{l}\text { Qu et al. }(2016 ; \mathrm{ScAc} \\
\text { condition) }\end{array}$ & $\begin{array}{l}\text { Chinese-English bilinguals } \\
(N=32) \\
\text { Chinese monolinguals }(N=32)\end{array}$ & $\begin{array}{l}\text { Young adults } \\
(21.1)\end{array}$ & $\begin{array}{l}\text { Computerized } \\
\text { DCCS }\end{array}$ & $\begin{array}{l}118 \text { trials ( } 40 \text { pure-repeat, } \\
10 \text { mixed-switch \& } 68 \\
\text { mixed-repeat) }\end{array}$ & $\begin{array}{l}\text { Bilinguals' switch-cost } \\
\text { advantage }\end{array}$ \\
\hline $\begin{array}{l}\text { Qu et al. }(2016 ; \mathrm{ScAc} \\
\text { condition) })^{3}\end{array}$ & $\begin{array}{l}\text { Chinese-English bilinguals } \\
(N=32) \\
\text { Chinese monolinguals }(N=32)\end{array}$ & $\begin{array}{l}\text { Young adults } \\
\text { (21.1) }\end{array}$ & $\begin{array}{l}\text { Computerized } \\
\text { DCCS }\end{array}$ & $\begin{array}{l}118 \text { trials ( } 40 \text { pure-repeat, } \\
10 \text { mixed-switch \& } 68 \\
\text { mixed-repeat) }\end{array}$ & $\begin{array}{l}\text { Bilinguals' switch-cost } \\
\text { advantage }\end{array}$ \\
\hline $\begin{array}{l}\text { Qu et al. }(2016 ; \mathrm{ScAc} \\
\text { condition) })^{3}\end{array}$ & $\begin{array}{l}\text { Chinese-English bilinguals } \\
(N=32) \\
\text { Chinese monolinguals } \\
(N=32)\end{array}$ & $\begin{array}{l}\text { Young adults } \\
\text { (21.1) }\end{array}$ & $\begin{array}{l}\text { Computerized } \\
\text { DCCS }\end{array}$ & $\begin{array}{l}118 \text { trials ( } 40 \text { pure-repeat, } \\
10 \text { mixed-switch \& } 68 \\
\text { mixed-repeat) }\end{array}$ & No bilingual advantages \\
\hline $\begin{array}{l}\text { Houtzager, Lowie, } \\
\text { Sprenger \& De Bot } \\
\text { (2015) }\end{array}$ & $\begin{array}{l}\text { Dutch-Frisian bilinguals }(N=50) \\
\text { German bilinguals }(N=50)\end{array}$ & Older adults (60.2) & $\begin{array}{l}\text { Color-shape } \\
\text { switching task }\end{array}$ & $\begin{array}{l}192 \text { trials ( } 96 \text { pure-repeat, } \\
48 \text { mixed-switch \& } 48 \\
\text { mixed-repeat) }\end{array}$ & $\begin{array}{l}\text { Bilinguals' switch-cost } \\
\text { advantage }\end{array}$ \\
\hline This Study & $\begin{array}{l}\text { English-Korean bilinguals }(N=37) \\
\text { English monolinguals }(N=35)\end{array}$ & $\begin{array}{l}\text { Young adults } \\
(20.3)\end{array}$ & $\begin{array}{l}\text { Computerized } \\
\text { DCCS }\end{array}$ & $\begin{array}{l}60 \text { trials ( } 30 \text { pure-repeat, } 12 \\
\text { mixed-switch \& } 18 \\
\text { mixed-repeat) }\end{array}$ & $\begin{array}{l}\text { Bilingual advantages in, } \\
\text { single-task switch costs, } \\
\text { reactivation benefits \& } \\
\text { mixing costs }\end{array}$ \\
\hline
\end{tabular}

Notes: Qu et al. (2015) manipulated cognitive demands of suppression and activation across four different task-switching tasks. ScAc = suppress one set of conflicting responses while simultaneously activating another set of conflicting responses; $\mathrm{ScAc}=$ suppress one set of conflicting responses while simultaneously activating another set of non-conflicting responses; $\mathrm{ScAc}=$ suppress one set of non-conflicting responses while simultaneously activating another set of conflicting responses; $\mathrm{ScAc}=$ suppress one set of non-conflicting responses while simultaneously activating another set of non-conflicting responses. DCCS $=$ Dimension Change Card Sort task. 


\section{References}

Arbuthnott, K., \& Frank, J. (2000). Trail making test, part B as a measure of executive control: validation using a setswitching paradigm. Journal of Clinical and Experimental Neuropsychology, 22, 518-528.

Barac, R., \& Bialystok, E. (2012). Bilingual effects on cognitive and linguistic development: Role of language, cultural background, and education. Child development, 83(2), 413-422.

Bialystok, E. (1999). Cognitive complexity and attentional control in the bilingual mind. Child Development, 70(3), 636-644.

Bialystok, E., Craik, F. I., Green, D. W., \& Gollan, T. H. (2009). Bilingual minds. Psychological Science in the Public Interest, 10, 89-129.

Bialystok, E., \& Feng, X. (2009). Language proficiency and executive control in proactive interference: Evidence from monolingual and bilingual children and adults. Brain and Language, 109, 93-100.

Bialystok, E., \& Martin, M. M. (2004). Attention and inhibition in bilingual children: Evidence from the dimensional change card sort task. Developmental science, 7(3), 325339.

Braver, T. S., Reynolds, J. R., \& Donaldson, D. I. (2003). Neural mechanisms of transient and sustained cognitive control during task-switching. Neuron, 39, 713-726.

Bowden, E. M., \& Jung-Beeman, M. (2003). Aha! Insight experience correlates with solution activation in the right hemisphere. Psychonomic Bulletin \& Review, 10, 730-737.

Calabria, M., Hernández, M., Martin, C. D., \& Costa, A. (2011). When the tail counts: The advantage of bilingualism through the ex-Gaussian distribution analysis. Frontiers in Psychology, 2, 250.

Carlson, S. M., \& Meltzoff, A. N. (2008). Bilingual experience and executive functioning in young children. Developmental Science, 11(2), 282-298.

Coderre, E. L., \& van Heuven, W. J. (2014). The effect of script similarity on executive control in bilinguals. Frontiers in Psychology, 5.

Costa, A., Hernández, M., Costa-Faidella, J., \& SebastiánGallés, N. (2009). On the bilingual advantage in conflict processing: Now you see it, now you don't. Cognition, 113, 135-149.

De Baene, W., Kühn, S., \& Brass, M. (2012). Challenging a decade of brain research on task switching: Brain activation in the task-switching paradigm reflects adaptation rather than reconfiguration of task sets. Human Brain Mapping, 33, 639-651.

Diamond, A. (2013). Executive functions. Annual Review of Psychology, 64, 135-168.

Diamond, A., \& Kirkham, N. (2005). Not quite as grown-up as we like to think parallels between cognition in childhood and adulthood. Psychological Science, 16(4), 291-297.

Dunn, L. M., \& Dunn, L. M. (1997). PPVT-III: Peabody picture vocabulary test. Circle Pines, MN: American Guidance Service.

Durston, S., Thomas, K. M., Worden, M. S., Yang, Y., \& Casey, B. J. (2002). The effect of preceding context on inhibition: An event-related fMRI study. Neuroimage, 16, 449-453.
Engel de Abreu, P. M., Cruz-Santos, A., Tourinho, C. J., Martin, R., \& Bialystok, E. (2012). Bilingualism enriches the poor: Enhanced cognitive control in low-income minority children. Psychological Science, 23(11), 1364-1371.

Frye, D., Zelazo, P. D., \& Palfai, T. (1995). Theory of mind and rule-based reasoning. Cognitive Development, 10, 483527.

Gade, M., \& Koch, I. (2014). Cue type affects preparatory influences on task inhibition. Acta psychologica, 148, 1218.

Garbin, G., Sanjuan, A., Forn, C., Bustamante, J. C., RodriguezPujadas, A., Belloch, V., Hernández, M., Costa, A., \& Avila, C. (2010). Bridging language and attention: Brain basis of the impact of bilingualism on cognitive control. NeuroImage, 53, 1272-1278.

Gold, B. T., Kim, C., Johnson, N. F., Kryscio, R. J., \& Smith, C. D. (2013). Lifelong bilingualism maintains neural efficiency for cognitive control in aging. The Journal of Neuroscience, 33, 387-396. doi:10.1523/ jneurosci.3837-12.2013

Gray, J. R. (2001). Emotional modulation of cognitive control: Approach-withdrawal states double-dissociate spatial from verbal two-back task performance. Journal of Experimental Psychology: General, 130(3), 436-452.

Goldberg, E., Podell, K., \& Lovell, M. (1994). Lateralization of frontal lobe functions and cognitive novelty. Journal of Neuropsychiatry and Clinical Neuroscience, 6, 371-378.

Green, D. W., \& Abutalebi, J. (2013). Language control in bilinguals: The adaptive control hypothesis. Journal of Cognitive Psychology, 25, 515-530.

Hartanto, A., \& Yang, H. (2016). Disparate bilingual experiences modulate task-switching advantages: A diffusion-model analysis of the effects of interactional context on switch costs. Cognition, 150, 10-19.

Hernandez, A. E., Greene, M. R., Vaughn, K. A., Francis, D. J., \& Grigorenko, E. L. (2015). Beyond the bilingual advantage: The potential role of genes and environment on the development of cognitive control. Journal of Neurolinguistics, 35, 109-119.

Hernández, M., Martin, C. D., Barcelo, F., \& Costa, A. (2013). Where is the bilingual advantage in task-switching? Journal of Memory and Language, 69, 257-276.

Houtzager, N., Lowie, W., Sprener, S., \& De Bot, K. E. E. S. (2015). A bilingual advantage in task switching? Agerelated differences between German monolinguals and Dutch-Frisian bilinguals. Bilingualism: Language and Cognition, 1-11.

Kiesel, A., Steinhauser, M., Wendt, M., Falkenstein, M., Jost, K., Philipp, A. M., \& Koch, I. (2010). Control and interference in task switching - A review. Psychological bulletin, $136(5), 849$.

Kirk, N. W., Fiala, L., Scott-Brown, K. C., \& Kempe, V. (2014). No evidence for reduced Simon cost in elderly bilinguals and bidialectals. Journal of Cognitive Psychology, 26(6), 640-648.

Koch, I., Prinz, W., \& Allport, A. (2005). Involuntary retrieval in alphabet-arithmetic tasks: Task-mixing and task-switching costs. Psychological Research, 69, 252-261. 
Kray, J., \& Lindenberger, U. (2000). Adult age differences in task switching. Psychology and Aging, 15, $126-147$.

Linck, J. A. (2015). Methods matter for critical reviews too. Cortex; a journal devoted to the study of the nervous system and behavior, 73, 354.

Linck, J. A., Schwieter, J. W., \& Sunderman, G. (2012). Inhibitory control predicts language switching performance in trilingual speech production. Bilingualism: Language and Cognition, 15(03), 651-662.

Logan, G. D., \& Bundesen, C. (2003). Clever homunculus: Is there an endogenous act of control in the explicit task-cuing procedure? Journal of Experimental Psychology: Human Perception and Performance, 29, 575-599.

Mayr, U. (2001). Age differences in the selection of mental sets: the role of inhibition, stimulus ambiguity, and response-set overlap. Psychology and aging, 16(1), 96.

Mayr, U., \& Kliegl, R. (2003). Differential effects of cue changes and task changes on task-set selection cost. Journal of Experimental Psychology: Learning, Memory, and Cognition, 29, 362-372.

Mednick, M. T., Mednick, S. A., \& Mednick, E. V. (1964). Incubation of creative performance and specific associative priming. The Journal of Abnormal and Social Psychology, $69,84-88$.

Meiran, N. (2000). Reconfiguration of stimulus task sets and response task sets during task switching. Control of cognitive processes: Attention and performance XVIII, 377-399.

Minear, M., Shah, P., \& Park, D. (2002). Training task-shifting skills in older adults. Poster presented at the 2002 meeting of the Cognitive Aging Conference, Atlanta, GA.

Monsell, S. (2003). Task switching. Trends in Cognitive Sciences, 7, 134-140.

Mor, B., Yitzhaki-Amsalem, S., \& Prior, A. (2015). The joint effect of bilingualism and ADHD on executive functions. Journal of attention Disorders, 19(6), 527-541.

Morey, R. D., Rouder, J. N., \& Jamil, T. (2014). BayesFactor: Computation of Bayes factors for common designs. $R$ package version $0.9,8$.

Morris, S. B., \& DeShon, R. P. (2002). Combining effect size estimates in meta-analysis with repeated measures and independent-groups designs. Psychological Methods, 7(1), $105-125$.

Morton, J. B., \& Harper, S. N. (2007). What did Simon say? Revisiting the bilingual advantage. Developmental Science, 10(6), 719-726.

Paap, K. R., Darrow, J., Dalibar, C., \& Johnson, H. A. (2014). Effects of script similarity on bilingual advantages in executive control are likely to be negligible or null. Frontiers in psychology, 5, 1539.

Paap, K. R., \& Greenberg, Z. I. (2013). There is no coherent evidence for a bilingual advantage in executive processing. Cognitive Psychology, 66, 232-258.

Paap, K. R., Johnson, H. A., \& Sawi, O. (2014). Are bilingual advantages dependent upon specific tasks or specific bilingual experiences?. Journal of Cognitive Psychology, 26(6), 615-639.

Paap, K. R., Johnson, H. A., \& Sawi, O. (2015). Bilingual advantages in executive functioning either do not exist or are restricted to very specific and undetermined circumstances. Cortex, 69, 265-278.

Paap, K. R., \& Sawi, O. (2014). Bilingual advantages in executive functioning: Problems in convergent validity, discriminant validity, and the identification of the theoretical constructs. Frontiers in Psychology, 5.

Poljac, E., Haan, A. D., \& Galen, G. P. V. (2006). Current task activation predicts general effects of advance preparation in task switching. Experimental Psychology, 53(4), 260-267.

Poljac, E., Koch, I., \& Bekkering, H. (2009). Dissociating restart cost and mixing cost in task switching. Psychological Research PRPF, 73, 407-416.

Prior, A., \& Gollan, T. H. (2011). Good language-switchers are good task-switchers: Evidence from Spanish-English and Mandarin-English bilinguals. Journal of the International Neuropsychological Society, 17, 682-691.

Prior, A., \& MacWhinney, B. (2010). A bilingual advantage in task switching. Bilingualism: Language and Cognition, 13, 253-262.

Qu, L., Low, J. J. W., Zhang, T., Li, H., \& Zelazo, P. D. (2016). Bilingual advantage in executive control when task demands are considered. Bilingualism: Language and Cognition, 19(02), 277-293.

Ratcliff, R. (1993). Methods for dealing with reaction time outliers. Psychological Bulletin, 114, 510-532.

Rogers, R. D., \& Monsell, S. (1995). Costs of a predictable switch between simple cognitive tasks. Journal of Experimental Psychology: General, 124, 207-231.

Rubin, O., \& Meiran, N. (2005). On the origins of the task mixing cost in the cuing task-switching paradigm. Journal of Experimental Psychology: Learning, Memory, and Cognition, 31, 1477-1491.

Salthouse, T. A. (2011). What cognitive abilities are involved in trail-making performance?. Intelligence, 39, 222-232.

Sanchez-Cubillo, I., Perianez, J. A., Adrover-Roig, D., Rodriguez-Sanchez, J. M., Rios-Lago, M., Tirapu, J. E. E. A., \& Barcelo, F. (2009). Construct validity of the Trail Making Test: role of task-switching, working memory, inhibition/interference control, and visuomotor abilities. Journal of the International Neuropsychological Society, $15,438-450$.

Schneider, D. W., \& Logan, G. D. (2011). Task-switching performance with 1: 1 and 2: 1 cue-task mappings: Not so different after all. Journal of Experimental Psychology: Learning, Memory, and Cognition, 37, 405-415.

Shiffrin, R. M., \& Schneider, W. (1977). Controlled and automatic human information processing: II. Perceptual learning, automatic attending and a general theory. Psychological review, 84(2), 127.

Soveri, A., Rodriguez-Fornells, A., \& Laine, M. (2011). Is there a relationship between language switching and executive functions in bilingualism? Introducing a withingroup analysis approach. Frontiers in Psychology, 2, 138-143.

Strobach, T., Liepelt, R., Schubert, T., \& Kiesel, A. (2012). Task switching: Effects of practice on switch and mixing costs. Psychological Research, 76, 74-83.

Weissberger, G. H., Gollan, T. H., Bondi, M. W., Clark, L. R., \& Wierenga, C. E. (2015). Language and task switching in 
the bilingual brain: Bilinguals are staying, not switching, experts. Neuropsychologia, 66, 193-203.

Wiseheart, M., Viswanathan, M., \& Bialystok, E. (2016). Flexibility in task switching by monolinguals and bilinguals. Bilingualism: Language and Cognition, 19(1), 141-146.

Wylie, G., \& Allport, A. (2000). Task switching and the measurement of "switch costs". Psychological Research, 63, 212-233.

Yang, H., Hartanto, A., \& Yang, S. (2016). The complex nature of bilinguals' language usage modulates task-switching outcomes. Frontiers in Psychology, 7.

Yang, H., \& Yang, S. (2014). Positive affect facilitates task switching in the dimensional change card sort task: Implications for the shifting aspect of executive function. Cognition and Emotion, 28, 1242-1254.

Yang, H., \& Yang, S. (2016). Are all interferences bad? Bilingual advantages in working memory are modulated by varying demands for controlled processing. Bilingualism: Language and Cognition, 20(1), 184-196.

Yang, H., Yang, S., \& Isen, A. M. (2013). Positive affect improves working memory: Implications for controlled cognitive processing. Cognition and Emotion. 27, 474-482.

Yang, S., Yang, H., \& Hartanto, A. (2016). Effects of script variations on executive attention among bilinguals: A comparison between alphabetic and logographic language combinations. Unpublished paper, Yonsei University.

Yang, S., Yang, H., \& Lust, B. (2011). Early childhood bilingualism leads to advances in executive attention: Dissociating culture and language. Bilingualism: Language and Cognition, 14(03), 412-422.

Yow, W. Q., \& Li, X. (2015). Balanced bilingualism and early age of second language acquisition as the underlying mechanisms of a bilingual executive control advantage: why variations in bilingual experiences matter. Frontiers in Psychology, 6 .

Zhou, B., \& Krott, A. (2016a). Data trimming procedure can eliminate bilingual cognitive advantage. Psychonomic Bulletin \& Review, 23(4), 1221-1230.

Zhou, B., \& Krott, A. (2016b). Bilingualism enhances attentional control in non-verbal conflict tasks-evidence from exGaussian analyses. Bilingualism: Language and Cognition, $1-19$. 